\title{
Successful Treatment of Cutaneous Botryomycosis with a Combination of Minocycline and Topical Heat Therapy
}

\author{
Masaya Ishibashi ${ }^{a} \quad$ Yukikazu Numata $^{\mathrm{b}}$ Hachiro Tagami ${ }^{\mathrm{b}}$ \\ Setsuya Aibab \\ ${ }^{a}$ Department of Dermatology, Tohoku University Hospital, and ${ }^{b}$ Department of \\ Dermatology, Tohoku University Graduate School of Medicine, Sendai, Japan
}

\section{Key Words}

Botryomycosis $\cdot$ Minocycline $\cdot$ Topical heat therapy

\section{Abstract}

Cutaneous botryomycosis is a chronic focal infection characterized by a granulomatous inflammatory response to bacterial pathogens such as Staphylococcus aureus. Treatment requires antibiotic therapy and may also require surgical debridement. We employed topical heat therapy and oral minocycline. The lesions became flattened and pigmented after 1 month. We consider that this simple treatment can be an effective and harmless complementary therapy for cutaneous botryomycosis.

\section{Introduction}

Skin staphylococcal infections usually show acute inflammatory skin changes such as impetigo and furuncles. However, certain individuals, possibly those with an immunodeficiency, may show a unique, chronic focal granulomatous lesion that is noted clinically as botryomycosis. To treat such a case, we employed topical heat therapy together with oral antibiotics to cure botryomycosis without using any surgical measures.

\section{Case Report}

A 53-year-old Japanese woman with a 6-year history of bronchial asthmatic attacks for which she occasionally used budesonide inhalation presented with a 3-month history of asymptomatic, scattered, red papules on the dorsum of the right foot (fig. 1). She denied any preceding trauma or 
surgical procedures at this site. The lesions gradually increased in size despite the tentative application of a topical corticosteroid. Thus, suspecting infectious granulomatous lesions, in addition to bacterial and fungal cultures we surgically removed one of the red papules for histopathological studies. Histopathologically, the papule showed the presence of basophilic bacterial granules surrounded by eosinophilic amorphous materials, constituting a typical Splendore-Hoeppli phenomenon in the mid-dermis [1] (fig. 2). The bacteriological culture of a part of the biopsy specimen yielded a colony of Staphylococcus aureus, whereas no other growth for fungi or actinomycetes could be observed. The results of the laboratory investigations excluded any risk factors such as diabetes mellitus, collagen disease or HIV infection. There was also no history of alcoholism. Despite the prolonged budesonide inhalation for bronchial asthma in the past, her neutrophil phagocytotic function and immunological parameters such as IgG levels and CD4 count were found to be all within normal limits. Based on these results, we made a diagnosis of cutaneous botryomycosis caused by $S$. aureus. Since the patient was allergic to a variety of drugs containing $\beta$-lactam antibiotics, we started oral administration of minocycline at a dose of $200 \mathrm{mg} /$ day together with topical heat therapy, using a commercially available, disposable pocket warmer. She applied the pack daily as long as possible, taking care not to cause a burn injury. With this treatment, we noticed substantial clinical improvement of the lesions after 1 month, and the treatment was continued for another 4 months until all lesions became flattened and pigmented (fig. 3 ). There was no subsequent relapse in the following 8 months.

\section{Discussion}

Botryomycosis is a unique, chronic bacterial granulomatous disease that often involves the skin, subcutaneous tissues and, rarely, the viscera [2]. Its treatment requires antibiotic therapy and, in most cases, surgical debridement. The selection of antibiotics should be tailored to the results of bacterial cultures [3]. Even though such patients may not show any signs of immunodeficiency, it sometimes happens that antibiotic therapy alone may be insufficient $[4,5]$.

The present patient did not show any laboratory-proven abnormalities in her immune system such as $\mathrm{T}$ cell defects, neutrophil function or a previous immunosuppressive condition associated with the history of other opportunistic infections. However, it was reported that $\mathrm{T}$ cell defects and impaired neutrophil, monocyte and/or macrophage function play a significant role in the development of botryomycosis [6]; therefore, we cannot exclude the possibility that her past 6-year history of occasional corticosteroid inhalation for the control of bronchial asthma might have influenced her immune system. In fact, botryomycosis occurs most commonly among immunocompromised patients [7]. Thus, besides antibiotic therapy, we also started topical heat therapy based on the findings that it was a safe and effective method for treating sporotrichosis and chromoblastomycosis when antifungal agents were not available in Japan [8]. The temperature of the commonly used heating packs, which are available as body warmers in Japan, rises up to $63^{\circ} \mathrm{C}$ and lasts $12 \mathrm{~h}$, with an average temperature of $53^{\circ} \mathrm{C}$ in wintertime. Being a source of heat, any device that emits constant heat to keep the skin surface temperature at $40-43^{\circ} \mathrm{C}$ should be wrapped with a piece of cloth because the skin cannot tolerate persistent heat higher than that $[8,9]$. Therefore, a temperature-dependent germicidal effect for $S$. aureus cannot be expected since the highest temperature limit for its growth is $48^{\circ} \mathrm{C}$ after 7 days of incubation [10].

Although the precise mechanisms underlying the effectiveness of topical heat therapy are not completely clear, we think that heat exerts at least a cytostatic effect on the organisms, which facilitates the phagocytic function of the host defense 
mechanisms in addition to its possible effect on host immunity. The skin surface temperature of the ankle is about $30^{\circ} \mathrm{C}$ [11]. An increase of the skin surface temperature from 30 to $43^{\circ} \mathrm{C}$ can lead to an increased blood flow, which would result in the increased activation of antibacterial defense. We consider that this simple treatment can be an effective and harmless complementary therapy for cutaneous botryomycosis. To our knowledge, this is the first report of botryomycosis successfully treated by minocycline combined with topical heat therapy.

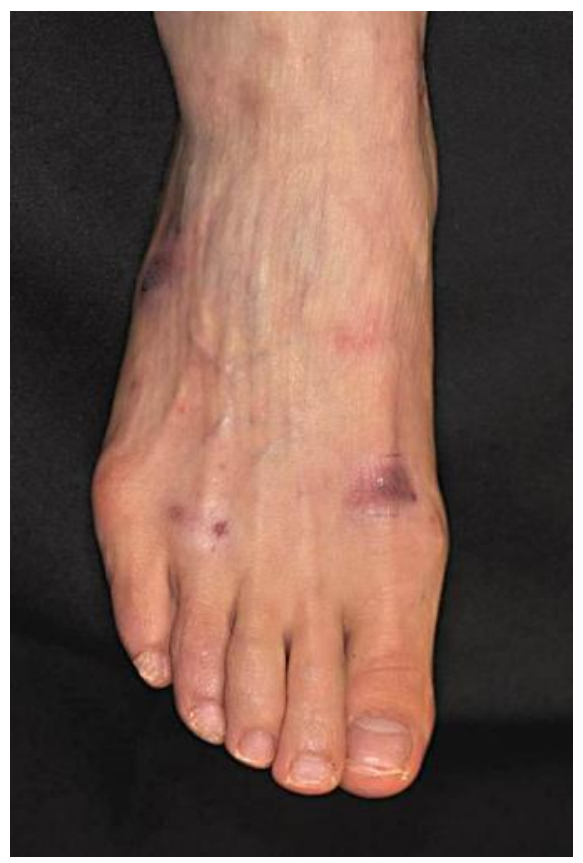

Fig. 1. Dark red papuloerythematous lesions on the dorsal and lateral side of the right foot. 

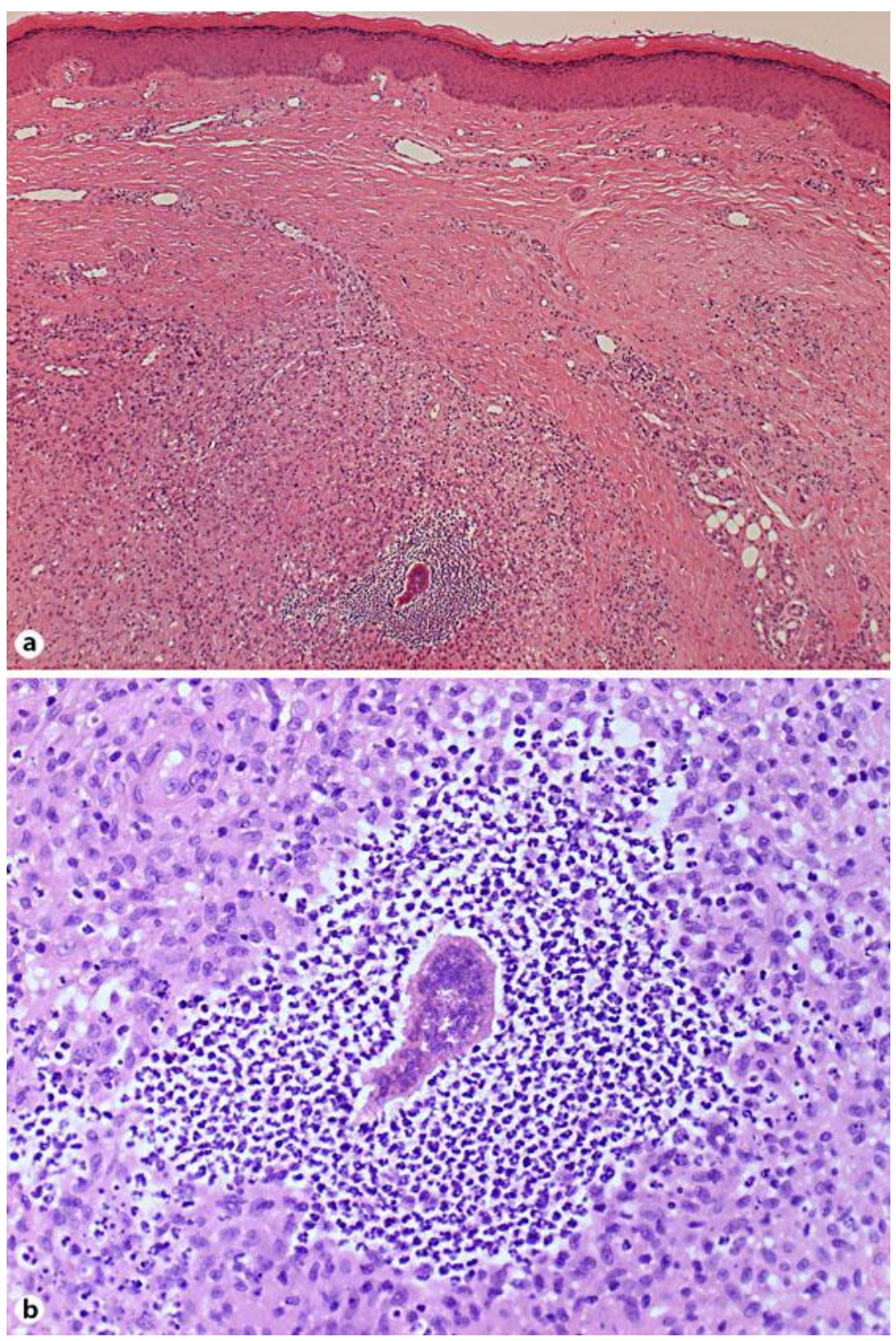

Fig. 2. a Basophilic granules surrounded by mixed cell granuloma in the lower dermis (original magnification $\times 50$ ). $\mathbf{b}$ Magnified feature of bacterial clumps. Grain surrounded by an eosinophilic material (the Splendore-Hoeppli phenomenon; original magnification $\times 200$ ). 


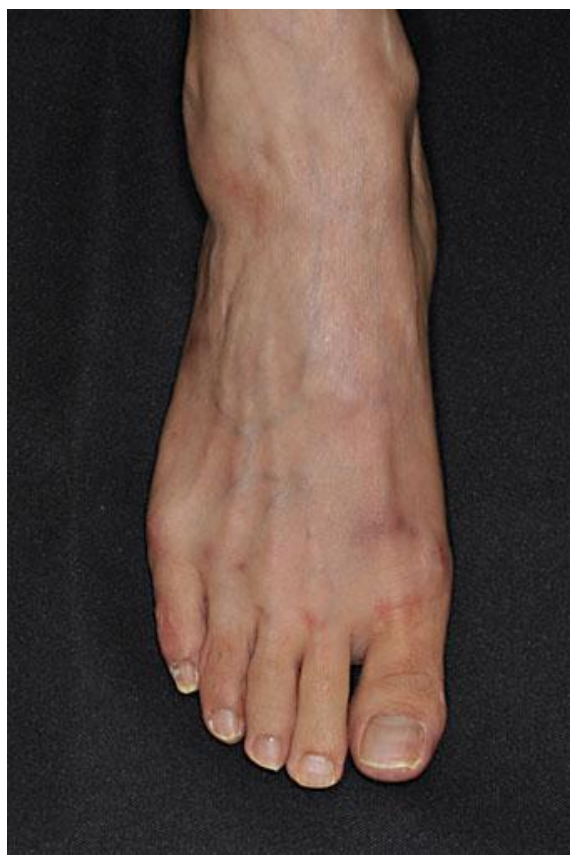

Fig. 3. Four months after the initial therapy.

\section{References}

1 Hussein M: Mucocutaneous Splendore-Hoeppli phenomenon. J Cutan Pathol 2008;35:979-988.

2 Bonifaz A, Carrasco E: Botryomycosis. Int J Dermatol 1996;35:381-388.

3 Neafie RC, Marty AM: Unusual infections in humans. Clin Microbiol Rev 1993;6:34-56.

-4 Takata T, Nakajima H, Ikeda M, Kodama H, Tamaki H, Sano S: Cutaneous botryomycosis associated with eosinophilic cellulitis. J Dermatol 2009;36:551-554.

5 Meissner M, Spieth K, Wolter M, Gille J, Boehncke WH, Thaci D, Kaufmann R: Cutaneous botryomycosis. A rarely diagnosed bacterial infection of the skin (in German). Hautarzt 2007;58:966-968.

-6 Saadat P, Ram R, Sohrabian S, Vadmal MS: Botryomycosis caused by Staphylococcus aureus and pneumocystis carinii in a patient with acquired immunodeficiency disease. Clin Exp Dermatol 2008;33:266-269.

7 Williams RH, Kattih M, Boyd WP, Morgan MB: Cecal botryomycosis: case report and review. Gastrointest Endosc 2003;57:783-785.

8 Tagami H, Ginoza M, Imaizumi S, Urano-Suehisa S: Successful treatment of chromoblastomycosis with topical heat therapy. J Am Acad Dermatol 1984;10:615-619.

$\checkmark 9$ Moritz AR, Henriques FC: Studies of thermal injury: II. The relative importance of time and surface temperature in the causation of cutaneous burns. Am J Pathol 1947;23:695-720.

10 Schmitt M, Schuler-Schmid U, Schmidt-Lorenz W: Temperature limits of growth, TNase and enterotoxin production of Staphylococcus aureus strains isolated from foods. Int J Food Microbiol 1990;11:1-19.

11 Mancuso DL, Knight KL: Effects of prior physical activity on skin surface temperature response of the ankle during and after a 30-minute ice pack application. J Athl Train 1992;27:242-249. 